\title{
Patients with Impairment of Multiple Joints after a Total Joint Replacement Benefit from Three Weeks' Intensive Exercise Training Directly Following Hospital Discharge.
}

\author{
Daan Ter Keurs ${ }^{1}$, Yvette Bulthuis ${ }^{2}$, Elgun Zeegers ${ }^{3}$, Mart Van de Laar $^{2}$ \\ 1. Gelre Ziekenhuis 2. Arthritis Centre Twente, Medisch Spectrum Twente \& University Twente 3. \\ Department for Orthopaedic surgery, Medisch Spectrum Twente
}

$\square$ Corresponding author: Daan Ter Keurs, d_ter_keurs@hotmail.com Disclosures can be found in Additional Information at the end of the article

Received 05/25/2013 Review began 05/26/2013 Published 06/08/2013

\section{(๑) Copyright 2013}

Ter Keurs et al. This is an open access article distributed under the terms of the Creative Commons Attribution License CC-BY 3.0., which permits unrestricted use, distribution, and reproduction in any medium, provided the original author and source are credited.

\section{Abstract}

Purpose: To examine the influence of a three weeks' intensive exercise training directly following hospital discharge for total hip or knee arthroplasty in patients with multiple joint disease, on physical function, quality of life, and general health.

Method: This is a post-hoc analysis of a subsection of 100 patients with elective hip or knee arthroplasty included in a previous randomized controlled trial. The intervention group ( $\mathrm{n}=53$ ) received intensive exercise training (IET) for three weeks in a dedicated resort; the control group ( $n=47$ ) was treated with usual care (UC). Outcomes were assessed at baseline and after three, 13, 26, and 52 weeks. Repeated measurement analyses were performed. The primary outcome was recovery of function measured by the HAQ.

Results: After three weeks and continuing over one year, the patients in the IET group benefited from the program significantly with respect to physical function (HAQ), quality of life (SF36), functional ability, and general health (MACTAR) as compared with the control group. The intensive training did not increase the pain.

Conclusions: Intensive exercise training with education immediately after hospital discharge has short- and long-term benefits for patients with multiple joint disease after total joint replacement surgery of hip and knee.

Categories: Physical Medicine \& Rehabilitation, Orthopedics

Keywords: intensive exercise therapy, disability evaluation, aftercare, total knee replacement, total hip replacement, randomized controled trial, arthritis

\section{Introduction}

Due to the senescence of the population, there is an increasing need for total joint replacement surgery i.e. for knee and hip joints [1-2]. In order to limit time spent during hospitalisation (primarily) and to restore functional ability rapidly (secondarily), several peri-operative training programmes and clinical pathways have been designed in the past [3-8]. These training programmes were used in relatively healthy patients [9-12]. Presently, the majority of hospitals in the Netherlands have introduced such a programme for their patients after total hip and knee

\section{How to cite this article}

Ter keurs D, Bulthuis Y, Zeegers E, et al. (June 08, 2013) Patients with Impairment of Multiple Joints after a Total Joint Replacement Benefit from Three Weeks' Intensive Exercise Training Directly Following Hospital Discharge.. Cureus 5(6): e122. DOI 10.7759/cureus.122 
surgery $[7,13]$. Although there are no standard inclusion criteria for these programmes, they are all focused on patients who generally rehabilitate more quickly and easily after surgery [12]. Therefore, most of the time healthy patients and patients with light systemic disease, according to the American Society of Anaesthesiology classification system (ASA class I or II) [14], are entered in these adjuvant training programmes [3, 15-16]. For more disabled patients, hospitalisation is considerably longer and restoring functional status is prolonged [17].

To the best of our knowledge, the effect of short intensive training in patients with multiple joint disease after hospital discharge has never been studied before 2002. In general, total joint replacement surgery and inactivity preoperative and during hospitalisation exacerbates the decline of physical fitness in both RA and OA patients [18].

Since intensive exercise has been demonstrated to benefit patients with joint diseases in some (inter)national studies [19-21], we formulated the hypothesis that patients with multiple joint disease will benefit from a dedicated rehabilitation and exercise programme in a resort supplementary to their hospital stay for joint arthroplasty.

Therefore, the purpose of the present randomised controlled study is to investigate whether these patients will benefit from an adjusted short-term intensive training programme after a total hip or knee replacement directly following hospital discharge.

\section{Materials And Methods}

\section{Patients}

For this study, a subsection of patients was used from the randomised controlled clinical trial called the DAPPER study (Disabled Arthritis Patients Post-hospitalisation Intensive Exercise Rehabilitation) [22]. The DAPPER study is a multicentre trial which examined the efficacy of short-term intensive exercise training directly following hospital discharge in patients with rheumatoid arthritis (RA) or osteoarthritis (OA). The patients in this study were eligible in case of exacerbation RA and elective total joint arthroplasty. For details, we refer to the principal publication mentioned above. For this subsection, patients were eligible when they were admitted for elective total hip or knee replacement. Additional inclusion criteria were: (a) age over 18, and (b) OA of multiple joints (polyarticular OA) or RA (according to American College of Rheumatology criteria 1987) [23]. Exclusion criteria were; (i) presence of serious cardiac disease (New York Heart Association criteria class III and IV) [24], (ii) incapacitating pulmonary disease (GOLD stage IV) [25], (iii) serious hypertension (diastolic blood pressure > $110 \mathrm{~mm} \mathrm{Hg}$ ), (iv) pregnancy, (v) insufficient mastery of the Dutch language, (vi) functional incapacity (Steinbrocker functional class 4) [26]. Ethical approval was given before the start of the study by the medical ethical revision boards of the attending hospital. A signed consent form was obtained from all participants.

\section{Design}

This study is a pre-planned post-hoc analysis of a subsection of patients, admitted for elective total knee or total hip replacement, included in a randomised controlled clinical trial. In all participating centres, consecutive eligible patients were informed of the study. Those who agreed to participate were randomised to either the IET or the UC group. We performed a blocked stratified randomisation, including stratification on centre. During hospitalisation, all patients were treated at the discretion of the attending physician. Directly following hospital discharge patients in the IET group were sent to a resort to receive three weeks' intensive exercise training (see below). After this, the IET group went back home. Depending on their situation, some of them received physical therapy once a week in the first few months afterwards. In contrast, after discharge the patients in the UC group received only usual care at 
the discretion of their attending physician. In general, usual care consists of either physical therapy by a local physical therapist, about once or twice a week, or temporary admission to a nursing home, for one to three months when applicable. Outcome assessments were performed at baseline (the moment the patient was considered well enough to be discharged from the hospital) and after three, 13, 26, and 52 weeks, all by the same experienced physiotherapist.

\section{Intervention}

As soon as wound healing and the general medical condition of the patient made discharge from the hospital safe, the IET patients went to a dedicated 'resort' directly following hospital discharge: European Care Residence \& Resort 'Groot Stokkert'. This resort offers hotel facilities and professional care for disabled people. These include exercise facilities and physical therapy dedicated to patients with impairment of the musculoskeletal system. During their three week stay, patients were trained twice a day by physical therapists, for $\sim 75$ minutes per session, depending on the capabilities of the individual patient. The goals of the training were improvement of range of motion, muscle strength, balance, aerobic capacity, physical function and activities of daily life. The therapy sessions were given individually as well as in groups. In the first two weeks, treatment focused on experienced individual limitations, appropriate to joint replacement (range of motion of affected joints, strength, aerobic capacity, and simple functionality, such as walking, climbing stairs, and getting up from a chair). Moreover, hydrotherapy was applied after sufficient wound healing. During the third week, the training also focused on the functional capacities in their daily lives in and around their home environment, as prioritised by the patient. A group education programme was given twice weekly. This programme was based on the self-management training for arthritis patients by Kate Lorig, modified for the Netherlands by Taal [27-28].

\section{Assessments/measures}

The Health-assessment Questionnaire $(\mathrm{HAQ})$ is a patient-reported outcome questionnaire developed to assess functional limitations in patients with rheumatic diseases [29-30]. The instrument contains 20 items on eight domains of life (arising, walking, dressing, eating, reach, grip, hygiene, and common activities). The Dutch version of the HAQ has been validated [31]. The subscales, walking and arising, were used to assess functional disability of the lower extremities [32]. The scores range from 0 (no disability) to three (severe disability). Clinically relevant improvements for the $\mathrm{HAQ}$ vary between 0.22 and 0.26 [33-34].

The MacMaster Toronto Arthritis (MACTAR) Patient Preference Disability Questionnaire is a disease-specific questionnaire [35]. An interviewer assesses at baseline which activities are most impaired and considered most important by the individual patient (maximum: five). The follow-up assessments focus on change in ability to perform these activities. The second part of the MACTAR evaluates the patient's health status by asking questions on general health, quality of life, and physical and emotional function. The baseline scores range from 39-59. The weighted MACTAR at follow-up assessments ranges from 21 to 77 points. Lower scores reflect better functional ability. The MACTAR has been validated in Dutch patients [36]. An improvement of three points can be argued to be clinically significant [37].

The EPM-ROM (Escola Paulista de Medicina - Range of Motion scale) is a disease-specific questionnaire, which measured the range of motion. This scale evaluates 10 joint movements that are important in the performance of basic activities of daily living (ADL). The score for each joint movement can vary from zero (no limitation) to three (severe limitation). The sum of the left and right side is divided by two. The total score varies from 0 to 30 [38].

Health-related Quality of Life (HrQoL) was measured using the short form 36 (SF36). The mental and physical component summary scales (SF36-MCS \& SF36-PCS) were used [39], as 
were the subscales, bodily pain (SF36-BP), physical function (SF36-PF), and mental health (SF36-MH). The SF36-BP is mostly used to assess pain and limitations due to daily activities. This generic instrument has been translated and validated for use in Dutch patients [40]. A variety of analyses have indicated that improvements of 5-10 points in subscales and 2.5-5 points in summary scales score represent minimal clinical important difference in arthritis patients [33].

Angst, et al. [41] have found that in a rehabilitation intervention, effects larger than $12 \%$ of baseline score ( $6 \%$ of maximal score) can be attained and detected as minimum clinically significant difference (MCID) by the transition method in the SF-36, in patients with osteoarthritis of the lower extremities.

Besides the SF36-BP, pain was also measured by the visual analog scale (VAS) for pain. The VAS is a $100-\mathrm{mm}$ one-dimensional scale from no pain (0) to extreme pain (100). The minimum clinically significant difference in VAS pain scores was found to be $9 \mathrm{~mm}$ [42].

\section{Statistical analysis}

Comparisons of the baseline scores were made using either the Mann-Whitney test or the Independent Student's T-test, where appropriate. For categorical variables, analyses were performed using Chi-square and Fisher Exact test statistics. All analyses were performed on an intention-to-treat principle. Between-group differences in continuous variables over time were assessed by analysis of repeated measurements using the SPSS procedure for mixed models. This method takes into account all measurements, including those between baseline and endpoint. Correction for baseline differences was performed. In the power calculation, we used the equation for sample size. In order to have an $80 \%$ chance of detecting a significant (at onesided $5 \%$ level) 0.3 point difference in mean HAQ score between the two groups, we needed at least 45 patients in the IET en UC group. All statistical analyses were performed using the statistical package SPSS 16.0 and utilizing 2-tailed tests with a significance level of alpha $=.05$.

\section{Results}

Between July 2002 and January 2004, 100 patients signed informed consent forms and were randomised to either the intervention (IET) or the control group (UC) (Figure 1). 


\section{Cureus}

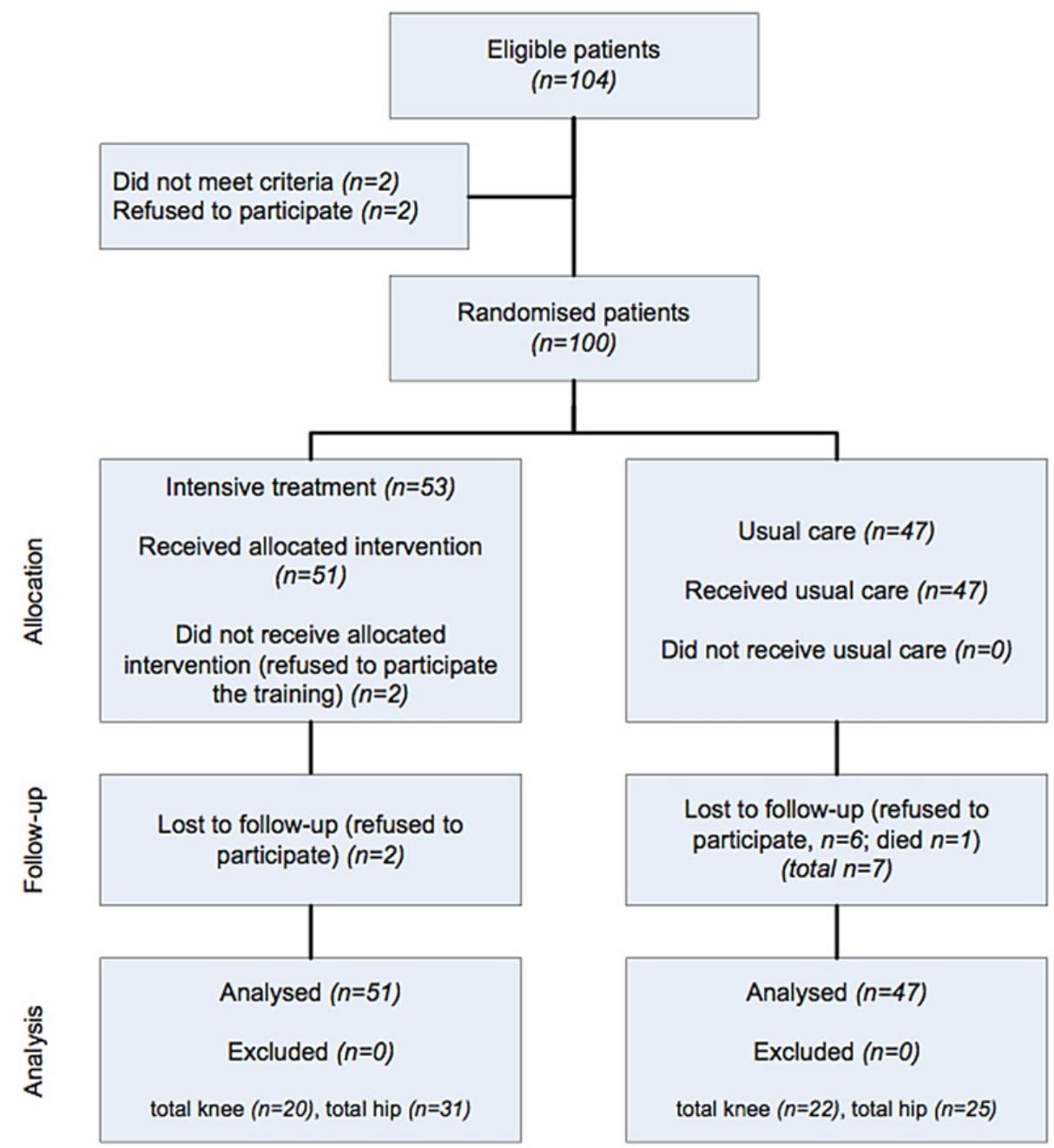

\section{FIGURE 1: Flow diagram of subject progress through this study}

In the UC group, one person died during the follow-up and two patients in the IET group refused to participate with all follow-up measures, due to work and mental state. From the total group ( $\mathrm{n}=98), 56$ patients were admitted for a total hip arthroplasty. Forty-two patients were admitted for total knee arthroplasty. The demographic and baseline characteristics of the patients are presented in Table 1. 


\section{Cureus}

\begin{tabular}{llll}
\hline Number of Patients & IET $(\mathbf{n = 5 1 )}$ & UC $(\mathbf{n = 4 7 )}$ & Total Sample $(\mathbf{n = 9 8})$ \\
\hline Age in years, mean (SD) & $70.4(10.8)$ & $67.3(11.2)$ & $69.0(11.0)$ \\
\hline Female, \% [n] & $82[42]$ & $83[39]$ & $83[81]$ \\
\hline Living alone, \% [n] & $49[25]$ & $38[18]$ & $44[43]$ \\
\% with one of more comorbidity beside arthritis [n] & $88[44]$ & $81[38]$ & $84[82]$ \\
Rheumatoid arthritis, \% [n] & $20[10]$ & $32[15]$ & $26[25]$ \\
\hline Total hip, \% [n] & $61[31]$ & $53[25]$ & $57[56]$ \\
Total knee, \% [n] & $39[20]$ & $47[22]$ & $43[42]$
\end{tabular}

TABLE 1: Baseline characteristics of the two treatment groups.

The mean age of the patients was 69 years $(S D=11)$. Comorbidities besides polyarticular OA or RA were present in $84 \%(n=82)$ of the patients. The most frequent comorbidities were hypertension (45\%) and heart failure (30\%). Of all patients, 33\% $(n=32)$ have had a joint replacement in the past. No significant differences were found at baseline between the IET and UC.

\section{Short-term effect of three weeks intensive training}

After three weeks of intensive training, the IET group improved relevantly more compared with the UC group, although not all differences reached statistical significance. The results of the repeated measurements analysis are presented in Table 2. 


\section{Cureus}

\begin{tabular}{|c|c|c|c|c|c|}
\hline & Baseline (Descriptive) & 3 Weeks (RMA*) & $\begin{array}{l}\text { Treatment Effect IET- } \\
\text { UC (RMA*) }\end{array}$ & & \\
\hline & IET $(n=51) /$ Mean $[S D]$ & UC $(n=47) /$ Mean [SD] & IET / mean [95\%Cl] & $\begin{array}{l}\text { UC / mean } \\
{[95 \% \mathrm{Cl}]}\end{array}$ & $\begin{array}{l}\Delta 3 \text { weeks }[ \\
95 \% \mathrm{Cl}]\end{array}$ \\
\hline $\begin{array}{l}\mathrm{HAQ} \\
\text { walking }\end{array}$ & $2.40[0.61]$ & $2.29[0.72]$ & $1.64[1.44 ; 1.85]$ & $\begin{array}{l}2.02[1.76 ; \\
2.29]\end{array}$ & $\begin{array}{l}0.38[0.05 ; 0.71] \\
p=.024\end{array}$ \\
\hline $\begin{array}{l}\mathrm{HAQ} \\
\text { rising }\end{array}$ & $1.76[0.60]$ & $1.54[0.72]$ & $1.18[0.97 ; 1.38]$ & $\begin{array}{l}1.50 \\
{[1.25 ; 1.76]}\end{array}$ & $\begin{array}{l}0.33[0.002 \\
0.66] p=.048\end{array}$ \\
\hline MACTAR & 46.3 [3.7] & 46.6 [3.5] & $34.5[32.5 ; 36.5]$ & $\begin{array}{l}41.3[38.9 ; \\
43.7]\end{array}$ & $\begin{array}{l}6.8[3.6 ; 9.9] \\
p=.000\end{array}$ \\
\hline $\begin{array}{l}\text { EPM- } \\
\text { ROM }\end{array}$ & $2.54[1.82]$ & $2.66[2.53]$ & $2.16[1.82 ; 2.49]$ & $\begin{array}{l}2.64[2.23 ; \\
3.05]\end{array}$ & $\begin{array}{l}0.49[-0.05 ; \\
1.02]\end{array}$ \\
\hline SF36-PF & $15.8[13.8]$ & $14.4[11.9]$ & $27.2[23.0 ; 31.5]$ & $\begin{array}{l}17.7[12.3 ; \\
23.0]\end{array}$ & $\begin{array}{l}-9.6[-16.4 ;- \\
2.7] p=.007\end{array}$ \\
\hline $\begin{array}{l}\text { SF36- } \\
\text { PCS }\end{array}$ & $25.2[7.3]$ & $24.0[4.8]$ & $27.6[26.3 ; 29.0]$ & $\begin{array}{l}25.9[24.1 ; \\
27.8]\end{array}$ & $-1.7[-4.0 ; 0.6]$ \\
\hline SF36-MH & 65.6 [22.3] & $63.2[16.7]$ & $72.0[67.5 ; 76.4]$ & $\begin{array}{l}71.1[65.5 ; \\
76.8]\end{array}$ & $-0.8[-8.1 ; 6.4]$ \\
\hline $\begin{array}{l}\text { SF36- } \\
\text { MCS }\end{array}$ & $48.1[13.3]$ & $45.9[12.1]$ & $49.6[46.9 ; 52.4]$ & $\begin{array}{l}47.4[43.7 ; \\
51.1]\end{array}$ & $-2.2[-6.8 ; 2.4]$ \\
\hline SF36-BP & $33.3[20.5]$ & $28.3[17.6]$ & $39.7[34.1 ; 45.3]$ & $\begin{array}{l}39.3[32.3 ; \\
46.3]\end{array}$ & $-0.38[-9.4 ; 8.6]$ \\
\hline VAS pain & $37.3[23.0]$ & $38.6[26.9]$ & $24.7[19.3 ; 30.0]$ & $\begin{array}{l}35.0[28.8 ; \\
41.2]\end{array}$ & $\begin{array}{l}10.3[2.1 ; 18.5] \\
p=.015\end{array}$ \\
\hline
\end{tabular}

\section{TABLE 2: 3-weeks effects of intensive exercise training versus usual care showing}

the data at baseline, after 3 weeks and the between group difference with the corresponding $95 \%$ confidence interval.

*Intention to treat analyses: results were obtained with repeated measurements analyses (RMA). NOTE: IET= intervention group, $\mathrm{UC}=$ control group, $\mathrm{HAQ}=$ Health-assessment Questionnaire , MACTAR= Toronto Arthritis Patient Preference Disability Questionnaire, EPM-ROM= Escola Paulista de Medicina - Range of Motion scale, SF36-PF= subscale physical function, SF36$\mathrm{PCS}=$ physical component summary scale, SF36-MH= mental health, SF36-MCS=mental component summary scale, SF36$\mathrm{BP}=$ bodily pain, VAS pain= visual analog scale pain 
The MACTAR score for the IET group compared with the UC group improved considerably. After three weeks, $94 \%$ of the IET group $(\mathrm{n}=48)$ showed a clinically relevant improvement on the MACTAR of more than three points compared with $73 \%$ in the UC group $(n=27), p=.006$. Also, with the separate questions of the MACTAR, the IET group was significantly more satisfied about their emotional and physical functioning, quality of life and general health after three weeks. Although the mobility (EPM-ROM) improved in the IET group compared with the UC group, this difference did not reach statistical significance.

The score on the subscale SF36-PF improved considerably for the IET group compared with the UC group. Seventy-five percent of the IET group $(n=36)$ showed a clinically relevant improvement on the SF36-PF after three weeks against $43 \%$ in the UC group $(n=13), p=.005$. As a practical example, stair climbing was much easier for the IET group after three weeks.

Based on the summary scales of the SF-36, physical component summary scale (SF36-PCS) and mental component summary scale (SF36-MCS), the general mental and physical health improved in the IET group. However, no significant differences were found between both groups. In the subscales SF36-MH and SF36-BP, no differences were found between both groups. However, both groups did show a relevant pain reduction in the first three weeks (SF36$\mathrm{BP})$. Measured with the VAS pain, the IET group experienced less pain after three weeks compared with the UC group, which is clinically relevant. Sixty-two percent of the IET group $(n=31)$ showed a clinically relevant improvement on the VAS pain against $35 \%(n=13)$ in the UC group ( $\mathrm{p}=.013$ ). Despite the fact, that they did not use more painkillers.

\section{Long-term effects of intensive training}

Also, over a period of three months and one year, the IET group improved relevantly more as compared with the UC group, although not all differences reached statistical significance. A significant between-group difference was found for the MACTAR, EPM-ROM and SF36-PF for the periods, three months and one year. At three months, the subscale HAQ rising also demonstrated a statistical difference. The results of the repeated measurements analysis are presented in Tables 3, 4 . 


\section{Cureus}

\section{Baseline (Descriptive) \\ 3 \\ Month (RMA*) \\ Treatment Effect IET- \\ UC (RMA*)}

IET $(n=51) /$ Mean [SD]

UC ( $n=47)$

/ Mean [SD]

IET / Mean [95\%Cl]

2.29 [0.72]

1.54 [0.72]

$\begin{array}{ll}\mathrm{HAQ} & 1.76[0.60]\end{array}$

MACTAR $\quad 46.3$ [3.7]

46.6 [3.5]

2.66 [2.53]

EPM-

2.54 [1.82]

ROM

SF36- PF 15.8 [13.8]

14.4 [11.9]

$32.8[28.8 ; 36.7]$

SF36-

PCS

$25.2[7.3]$

$24.0[4.8]$

$29.5[28.0 ; 31.1]$

SF36-

$\mathrm{MH}$

65.6 [22.3]

63.2 [16.7]

$72.2[68.5 ; 76.0]$

SF36-

MCS

48.1 [13.3]

45.9 [12.1]

51.5 [49.0; 54.1]

SF36-BP 33.3 [20.5]

VAS Pain $37.3[23.0]$

$1.43[1.25 ; 1.62]$

$0.99[0.83 ; 1.14]$

$34.1[32.1 ; 36.0]$

$1.98[1.69 ; 2.27]$

$28.3[17.6]$

$44.0[39.1 ; 48.8]$

26.1 [21.2; 31.1]
3.03]

25.0 [20.0;

30.0]

27.9 [25.9; 30.0]

71.2 [66.4;

75.9]

$-1.1[-7.2 ; 5.0]$

$49.2[45.6$

52.8]

$-2.3[-6.7 ; 2.0]$

42.8 [36.7;

49.0]

$-1.1[-9.0 ; 6.7]$

33.2 [27.4;

39.1]

$\Delta$ overall 3 months

[95\% Cl]

$0.23[-0.07 ; 0.53]$

0.27 [0.02; 0.51]

$\mathrm{p}=.034$

$5.8[2.9 ; 8.7] p=.000$

$0.71[0.26 ; 1.15]$

$\mathrm{p}=.002$

$-7.8[-14.0 ;-1.6]$

$\mathrm{p}=.015$

$-1.6[-3.9 ; 0.7]$

\section{TABLE 3: Long-term effect of intensive exercise training versus usual care showing}

the data at baseline, and during one year including the between-group difference with the corresponding $95 \%$ confidence interva

*Intention to treat analyses: results were obtained with repeated measurements analyses. NOTE: IET= intervention group, UC= control group, $\mathrm{HAQ}=$ Health-assessment Questionnaire , MACTAR= Toronto Arthritis Patient Preference Disability Questionnaire, EPM-ROM= Escola Paulista de Medicina - Range of Motion scale, SF36-PF= subscale physical function, SF36-PCS= physical component summary scale, SF36-MH= mental health, SF36-MCS=mental component summary scale, SF36-BP=bodily pain, VAS pain= visual analog scale pain 


\section{Cureus}

\begin{tabular}{|c|c|c|c|c|c|}
\hline & Baseline (Descriptive) & One Year (RMA*) & $\begin{array}{l}\text { Treatment Effect } \\
\text { IET-UC (RMA*) }\end{array}$ & & \\
\hline & IET $(n=51) /$ Mean (SD) & UC $(n=47) /$ Mean (SD) & IET/Mean $[95 \% \mathrm{Cl}]$ & $\begin{array}{l}\text { UC / Mean } \\
{[95 \% \mathrm{Cl}]}\end{array}$ & $\begin{array}{l}\Delta \text { overall one } \\
\text { year }[95 \% \mathrm{Cl}]\end{array}$ \\
\hline $\begin{array}{l}\mathrm{HAQ} \\
\text { walking }\end{array}$ & $2.40[0.61$ & $2.29[0.72]$ & $1.25[1.07 ; 1.43]$ & $\begin{array}{l}1.43[1.20 ; \\
1.65]\end{array}$ & $0.17[-0.10 ; 0.45]$ \\
\hline $\begin{array}{l}\mathrm{HAQ} \\
\text { rising }\end{array}$ & $1.76[0.60]$ & $1.54[0.72]$ & $0.85[0.71 ; 0.98]$ & $\begin{array}{l}1.05[0.88 ; \\
1.22]\end{array}$ & $0.20[-0.02 ; 0.42]$ \\
\hline MACTAR & $46.3[3.7]$ & $46.6[3.5]$ & $34.0[31.9 ; 36.0]$ & $\begin{array}{l}40.0[37.7 ; \\
42.2]\end{array}$ & $\begin{array}{l}6.0[3.1 ; 8.8] \\
p=.000\end{array}$ \\
\hline $\begin{array}{l}\text { EPM- } \\
\text { ROM }\end{array}$ & $2.54[1.82]$ & $2.66[2.53]$ & $1.98[1.71 ; 2.26]$ & $\begin{array}{l}2.66[2.34 ; \\
2.97]\end{array}$ & $\begin{array}{l}0.67[0.25 ; 1.09] \\
p=.002\end{array}$ \\
\hline SF36-PF & $15.8[13.8]$ & 14.4 [11.9] & $37.2[32.7 ; 41.6]$ & $\begin{array}{l}29.8[24.4 ; \\
35.1]\end{array}$ & $\begin{array}{l}-7.4[-13.5 ;- \\
1.3] p=.019\end{array}$ \\
\hline $\begin{array}{l}\text { SF36- } \\
\text { PCS }\end{array}$ & $25.2[7.3]$ & $24.0[4.8]$ & 31.7 [30.0; 33.4] & $\begin{array}{l}30.4 \text { [28.3; } \\
32.5]\end{array}$ & $-1.3[-3.5 ; 0.8]$ \\
\hline $\begin{array}{l}\text { SF36- } \\
\text { MH }\end{array}$ & 65.6 [22.3] & 63.2 [16.7] & $71.8[68.1 ; 75.6]$ & $\begin{array}{l}69.6[64.7 ; \\
74.3]\end{array}$ & $-2.3[-8.3 ; 3.8]$ \\
\hline $\begin{array}{l}\text { SF36- } \\
\text { MCS }\end{array}$ & 48.1 [13.3] & $45.9[12.1]$ & $51.1[48.6 ; 53.7]$ & $\begin{array}{l}48.9[45.5 ; \\
52.3]\end{array}$ & $-2.2[-6.5 ; 2.0]$ \\
\hline SF36-BP & 33.3 [20.5] & $28.3[17.6]$ & $49.0[44.5 ; 53.4]$ & $\begin{array}{l}48.5[42.9 ; \\
54.1]\end{array}$ & $-0.5[-7.7 ; 6.7]$ \\
\hline VAS Pain & $37.3[23.0]$ & 38.6 [26.9] & $27.9[22.9 ; 32.9]$ & $\begin{array}{l}34.8[29.2 ; \\
40.4]\end{array}$ & $6.9[-0.25 ; 14 .($ \\
\hline
\end{tabular}

\section{TABLE 4: Long-term effect of intensive exercise training versus usual care showing}

the data at baseline, and during one year including the between-group difference with the corresponding $95 \%$ confidence interva

*Intention to treat analyses: results were obtained with repeated measurements analyses. NOTE: IET= intervention group, UC= control group, $\mathrm{HAQ}=$ Health-assessment Questionnaire , MACTAR= Toronto Arthritis Patient Preference Disability Questionnaire, EPM-ROM= Escola Paulista de Medicina - Range of Motion scale, SF36-PF= subscale physical function, SF36-PCS= physical component summary scale, SF36-MH= mental health, SF36-MCS=mental component summary scale, SF36-BP=bodily pain, VAS pain $=$ visual analog scale pain 
0.22 points against $61 \%(\mathrm{n}=22)$ in the UC group $(\mathrm{p}=.007)$. Of the IET group, $80 \%(\mathrm{n}=40)$ showed a clinical relevant improvement on the subscale HAQ against $53 \%(n=17)$ in the UC group $(p=.010)$. With the MACTAR, 90\% $(n=46)$ of the IET group showed a relevant improvement of at least 3.0 points against $74 \%(n=28)$ in the UC group $(p=.040)$. With the subscale SF36-PF $78 \%$ of the IET group $(n=39)$ demonstrated a relevant improvement of 5.0 points and more compared with $60 \%(n=18)$ of the UC group ( $p=.085, n s)$.

Over a period of one year, a clinical relevant between-group difference was found for the IET group in the MACTAR and SF36-PF. Of the IET group, 90\% $(n=46)$ showed a clinical relevant improvement on the MACTAR against $77 \%(n=33)$ in the UC group $(p=.076, n s)$. With the subscale SF36-PF, 80\% of the IET group $(n=40)$ improved more than five points compared with $71 \%$ in the UC group (ns).

To the best of our knowledge, the EPM-ROM has no minimal important clinical difference. However, we noticed that during the first year after surgery $95 \%$ of the IET group improved their mobility as measured with the EPM-ROM. In the UC group, several patients experienced a decrease of mobility according to baseline, whereas in the IET group, none experienced a decline of mobility when compared with baseline scores.

With respect to baseline, both groups reported a clinically relevant improvement after one year. Practically, after one year a higher percentage of the IET patients were able to climb stairs and come out of bed without any problems or devices. These patients also experienced fewer disabilities, especially for walking a distance of 100 metres. Also, with the separate question of the MACTAR about the patients' general physical functioning, $84 \%$ of the IET group experienced a reasonable to good physical functioning compared with $63 \%$ of the UC group after one year $(p=.021)$. On the summary scale mental health, $61 \%$ of the IET group against $42 \%$ of the UC group $(n=10)$ experienced an improvement of more than 2.5 points after one year $(p=.132)$.

\section{Discussion}

This study demonstrates the beneficial effects (short-term as well as long-term) of a three week intensive exercise programme for patients with impairment of multiple joints and comorbidity directly following a hospital stay after total joint replacement. After three weeks, the patients in the IET group were more satisfied about their functional ability, physical and emotional functioning, quality of life, and general health. After one year, the patients in the IET group experienced a significantly improved physical function, an improved functional ability and an improved mobility. Based on the results of pain measures, we can conclude that the intensive training did not cause more pain, despite equal use of painkillers.

The used elements in our training program, such as individual dynamic and high intensity approach adapted to individual goals and desires, are supported lately in different studies - just like the combination of exercise and education in training programms. Hakkinen, et al. [43] found that moderate or high-intensity strength training programs have better effects on muscle strength in RA than low-intensity programs. Fransen, et al. [44] found consistent evidence that regular graded therapeutic exercise provides at least a short-term benefit for patients with arthritis. Bade, et al. [45] found evidence that strength and functional gains can be made after the acute postoperative recovery period.

Riemsma [46] and Bartlett [47] found that traditional patient education, focusing on transmitting knowledge or information, has limited impact compared to forms of patient education that focus on helping patients to incorporate change in behaviour. A review of international guidelines concluded that the best non-pharmacological care for OA consists of 
education as well as exercise [48]. Culliton, et al. [49] note even that patient education programs should be a part of the postoperative recovery period for better managing expectations.

Nowadays, rehabilitation programs are more and more focused on improvement of movement of joints and recovery of function in general, adapted to individual goals and desires [50]. SarziPuttini, et al. [51] implies that apart from generic strategies, individualized treatment components are needed. Any therapeutic program needs to take into account that OA is a heterogeneous condition, so each patient has different symptoms, signs, and functional limitations. Moreover, the therapeutic program should include a combination of physical measures, medical measures, psychological approaches, and surgical interventions.

In this trial, RA patients made up a sizeable $25 \%$ of the study population. For orthopaedic surgeons, the difference between RA and OA patients is of less relevance. RA patients with indication for prosthesis are treated similar in rehabilitation interventions. However, the expectations and satisfaction are higher in RA patients [52].

The program was focused on the improvement of general physical condition and not specifically on the hip or knee. Therefore, we did not show specific analyses between THA and TKA. However, based on first analyses, we found no specific differences in the trends between THA and TKA patients. This is in line with the expectations.

Based on the age and the percentage of comorbidities, as presented in Table 1, we conclude that the participants in this study mainly consists of ASA II and III patients [14]. Our study showed that an intensive exercise programme adapted for patients with impairment of multiple joints and comorbidity is beneficial. The programme is a good alternative for persons who cannot meet the criteria of such an existing programme during hospital stay as described in the introduction, because of substantial functional disabilities or comorbidity.

Our programme was not limited to intensive exercise and education only. For obvious reasons, the programme was provided in a dedicated hotel facility. In this resort, people could fully focus on their training and rehabilitation without worrying about everyday life, such as cleaning, cooking or shopping.

As in every study, our study has its strengths and limitations. Strong points of this study are the randomised controlled design with a considerable number of patients. Moreover, the intention to treat analysis meaning that all patients who were assigned to the study at baseline were included in the analysis underscores the strengths of the study. A limitation of our study was that the assessments were not blinded. Obviously, taking the informed consent obligation seriously, blinding is nearly impossible in clinical trials other than drug trials. Therefore, in this type of study, assessor bias is almost impossible to prevent.

In 2009, Minns wrote, "there is a need for well-designed trials to determine the value of post discharge exercise" [53] and "there is also a lack of guidelines for the appropriate amount and type of physical activity after surgery" [54]. The use of rehabilitation services is an understudied aspect of joint replacement. With this study result and above-described founding in literature, we hope to contribute how to use rehabilitation after joint replacement.

\section{Conclusions}

The results of this study should have implications for the care of patients after total joint replacement. This study indicates that intensive training and education in a dedicated resort is effective for patients with impairment of multiple joints. In conclusion, this study shows that 
physical recovery as well as (physical) functioning benefits for such patients after a total hip or knee arthroplasty.

\section{Additional Information}

\section{Disclosures}

Human subjects: All authors have confirmed that this study did not involve human participants or tissue. Animal subjects: All authors have confirmed that this study did not involve animal subjects or tissue. Conflicts of interest: In compliance with the ICMJE uniform disclosure form, all authors declare the following: Payment/services info: All authors have declared that no financial support was received from any organization for the submitted work. Financial relationships: All authors have declared that they have no financial relationships at present or within the previous three years with any organizations that might have an interest in the submitted work. Other relationships: All authors have declared that there are no other relationships or activities that could appear to have influenced the submitted work.

\section{Acknowledgements}

The authors wish to express their appreciation for the collaboration of all participating patients, nurses, physiotherapists and physicians. Moreover, we are very grateful for the fruitful collaboration with European Care Residence \& Resort 'Groot Stokkert' and the Dutch Arthritis Foundation.

\section{References}

1. Ostendorf M, Johnell O, Malchau H, Dhert WJ, Schrijvers AJ, Verbout AJ: The epidemiology of total hip replacement in The Netherlands and Sweden: Present status and future needs. Acta Orthop Scand. 2000, 73:282-6.

2. Jones DL, Westby MD, Greidanus N, Johanson NA, Krebs DE, Robbins L, Rooks DS, Brander V: Update on hip and knee arthroplasty: Current state of evidence. Arthritis Care Res. 2005, 53:772-80.

3. Stevens M, van den Akker-Scheek I, Spriensma A, Boss NAD, Diercks RL, van Horn JR: The Groningen Orthopedic Exit Strategy (GOES):a home-based support program for total hip and knee arthroplasty patients after shortened hospital stay. Patient Education and Counseling. 2004, 54:95-9.

4. van der Aast M, van Haastregt J: “Operatie heup”- een inventariserend onderzoek naar de mogelijkheden en onmogelijkheden van opnameduurverkorting bij mensen die een heupoperatie hebben ondergaan. TNO, Leiden; 1994.

5. Lin CC, March L, Crosbie J, Crawford R, Graves S, Naylor J, Harmer A, Jan S, Bennell K, Harris I, Parker D, Moffet H, Fransen M: Maximum recovery after knee replacement - the MARKER study rationale and protocol. BMC Musculoskeletal Disorders . 2009, 10:69-76.

6. Peerbhoy D, Keane P, Maciver K, Shenkin A, Hall GM, Salmon P: The systematic assessment of short-term functional recovery after major joint arthroplasty. J Qual Clin Pract. 1999, 19:165-71.

7. Pilot P, Engelen M, Dreessen F, van Os JJ, Kuipers H : Critical pathway for hip and knee arthroplasty: Faster home due to multidisciplinairy cooperation. Journal of Integrated care pathways. 2006, 9:1-4.

8. Lenssen AF, Crijns YHF, Waltjé EMH, van Steyn MJA, Geesink RJT, van den Brandt PA, de Bie RA: Efficiency of immediate postoperative inpatient physical therapy following total knee arthroplasty: An RCT. BMC Musculoskeletal Disorders. 2006, 7:71-9.

9. Ostendorf M, Johnell O, Malchau H, Dhert WJ, Schrijvers AJ, Verbout AJ: The Epidemiology of total hip replacement in The Netherlands and Sweden, present status and future needs. Acta Orthop Scand. 2002, 73:282-86.

10. Trudelle-Jackson E, Smith SS: Effects of a late-phase exercise program after total hip arthroplasty: A randomized controlled trial. Arch Phys Med Rehabil. 2004, 85:1056-62.

11. Wang AW, Gilbey HJ, Ackland TR: Perioperative exercise programs improve early return of 
ambulatory function after total hip arthroplasty: A Randomized, controlled trial. Am J Phys Med Rehabil. 2002, 81:801-6.

12. Berend KR, Lombardi AV Jr., Mallory TH: Rapid recovery protocol for peri-operative care of total hip and total knee arthroplasty patients. Surg Technol Int . 2004, 13:239-47.

13. Legierse C, Hardus K, van Rijnsoever M et al.: Quality compared [kwaliteit vergeleken]. Med Cont. 2004, 59:1990-3.

14. Ament R: Origin of the ASA classification. Anesthesiology. 1977, 51:179.

15. Bogie R: Goede resultaten heup-knieprogramma. Medisch Contact. 2005, 60:496-98.

16. van den Akker-Scheek I: Recovery after short-stay total hip and knee arthroplasty. Evaluation of a support program and outcome determination. St. Drukkerij C.Regenboog, Groningen; 2007.

17. Greenfield S, Apolone G, McNeil BJ, Cleary PD: The importance of co-existent disease in the occurrence of postoperative complications and one-year recovery in patients undergoing total hip replacement. Comorbidity and outcomes after hip replacement. Med Care. 1993, 31:141.

18. Maire J, Tordi N, Parratte B, Lonsdorfer J, Rouillon JD: Cardiovascular deconditioning in elderly with hip osteoarthrosis and benefits of reconditioning program after total hip arthroplasty. Science Sport. 2002, 17:155-65.

19. Munin MC, Rudy TE, Glynn NW, Crossett LS, Rubash HE: Early inpatient rehabilitation after elective hip and knee arthroplasty. Jama. 1998, 279:847-52.

20. Ekdahl C, Andersson SI, Moritz U, Svensson B: Dynamic versus static training in patients with rheumatoid arthritis. Scand J Rheumatol . 1990, 19:17-26.

21. Hopman-Rock M, Westhoff MH: The effects of a health educational and exercise program for older adults with osteoarthritis for hip and knee. J Rheumatol. 2000, 27:1947-54.

22. Bulthuis Y, Dorssaers-Bakker KW, Taal E, Rasker J, Oostveen J, van’t Pad Bosch P, Oosterveld F, van de Laar M: Arthritis patients show long-term benefits from 3 weeks intensive exercise training directly following hospital discharge. Rheumatology. 2007, 46:1712-17.

23. Arnett FC, Edworthy SM, Bloch DA, McShane DJ, Fries JF, Cooper NS et al. : The American Rheumatism Association 1987 revised criteria for the classification of rheumatoid arthritis. Arthritis Rheum. 1988, 31:315-24.

24. The Criteria Committee of the New York Heart Association: Nomenclature and Criteria for Diagnosis of Diseases of the Heart and Great Vessels, 9th Ed. Little, Brown and Company, New York, NY; 1994.

25. Rabe KF, Hurd S, Anzueto A, Barnes PJ, Buist SA, Calverley P, et al.: Global Strategy for the Diagnosis, Management, and Prevention of Chronic Obstructive Pulmonary Disease GOLD Executive Summary. Am J Respir Crit Care Med. 2007, 176:532-55.

26. Steinbrocker O, Traeger CH, Batterman RC: Therapeutic criteria in rheumatoid arthritis. J Am Med Ass. 1949, 140:659-62.

27. Lorig K, Lubeck D, Kraines RG, Seleznick M, Holman HR: Outcomes of self help education for patients with arthritis. Arthritis Rheum. 1985, 28:680-85.

28. Taal E, Rasker JJ, Wiegman O: Patient education and self-management in the rheumatic diseases: A self-efficacy approach. Arthritis Care Res. 1996, 9:229-38.

29. Bruce B, Fries JF : Review article. The Stanford Health Assessment Questionnaire: A review of its history, issues, progress and documentation. J Rheumatol. 2003, 30:167-78.

30. Bruce B, Fries JF: The Stanford Health Assessment Questionnaire: dimensions and practical applications. Health Qual Life Outcomes. 2003, 1:20.

31. Siegert CE, Vleming LJ, Van denbroucke JP, Cats A: Measurements of disability in Dutch rheumatoid arthritis patients. Clin Rheumatol. 1984, 3:305-9.

32. Walker DJ, Heslop PS, Chandler C, Cleary R: Extraction and validation of a lower limb HAQ by comparison with objective measurement of ambulatory activity. Scand J Rheumatol . 2001, 30:154-8.

33. Wolfe F, Michaud K, Strand V: Expanding the definition of clinical differences: From minimally clinically important differences to really important differences. Analyses in 8931 patients with rheumatoid arthritis. J of Rheum. 2005, 32:583-89 .

34. Kosinki M, Zhao SZ, Dedhiya S, Osterhaus JT, Ware JE jr: Determining minimally important changes in generic and disease-specific health-related quality of life questionnaires in clinical trials of rheumatoid arthritis. Arthritis \& Rheumatism. 2000, 43:1478-87.

35. Tugwell P, Bombardier C, Buchanan WW, Goldsmith CH, Grace E, Hanna B: The MACTAR patient preference disability questionnaire - an individualized functional priority approach for 
assessing improvement in physical disability in clinical trials in rheumatoid arthritis. J Rheumatol . 1987, 14:446-51.

36. Verhoeven AC, Boers M, van der Linden S: Validity of the MACTAR questionnaire as a functional index in a rheumatoid arthritis clinical trial. J Rheumatol. 2000, 27:2801-9.

37. Van der Hout WB, de Jong Z, Munneke M, Hazes JMW, Breedveld FC, Vliet Vlieland TPM: Cost-Utility and cost-effectiveness analyses of a long-term, high-intensity exercise program compared with conventional physical therapy in patients with rheumatoid arthritis. Arthritis Care Res. 2005, 53:39-47.

38. Vliet Vlieland TPM, van den Ende CHM, Breedveld FC, Hazes JMW: Evaluation of joint mobility in rheumatoid arthritis trials: The value of the EPM-range of motion scale. J Rheumatol. 1993, 20:2010-4.

39. Ware JE, Kosinski M, Keller SD: Physical and mental health summary scales- a user's manual . New England Medical Center, The Health Institute, Boston, MA; 1994.

40. Angst F, Aeschlimann A, Stucki G: Smallest detectable and minimal clinically important differences of rehabilitation intervention with their implications for required sample sizes using WOMAC and SF-36 quality of life measurement instruments in patients with osteoarthritis of the lower extremities. Arthritis Care Res. 2001, 45:384-91.

41. van der Zee KI, Sanderman R, Heyink J: De psychometrische kwaliteiten van de MOS 36-item Short Form Health Survey (SF-36) in een Nederlandse populatie. Tijdschrift voor Sociale gezondheidszorg. 1993, 4:183-91.

42. Kelly AM: Does the clinically significant difference in visual analog scale pain scores vary with gender, age or cause of pain?. Acad Emerg Med. 1998, 5:1086-90.

43. Häkkinen A: Effectiveness and safety of strength training in rheumatoid arthritis . Curr Opin Rheumatol. 2004, 16:132-7.

44. Fransen M: When is physiotherapy appropriate?. Best Practice \& Research Clinical Rheumatology. 2004, 18:477-89.

45. Bade MJ, Stevens-Lapsley JE: Restoration of physical function in patients following total knee arthroplasty: an update on rehabilitation practices. Curr Opin Rheumatol. 2012, 24:208-14.

46. Riemsma RP, Taal E, Kirwan JR, Rasker JJ: Systematic review of Rheumatoid Arthritis Patient education. Arthritis Rheum (Arthritis Care Res). 2004, 51:1045-59.

47. Bartlett SJ, Bingham CO, Maricic MJ, Iversen MA, Ruffing V : Clinical Care in the Rheumatic Diseases. 3rd edition. Association of Rheumatology Health Professionals, a Division of the American College of Rheumatology, Atlanta; 2006.

48. Pencharz JN, Grigoriadis E, Jansz GF, Bombardier C: A critical appraisal of clinical practice guidelines for the treatment of lower-limb osteoarthritis. Arthritis Research. 2002, 4:36-43.

49. Culliton SE, Bryant DM, Overend TJ, Macdonald SJ, Chesworth BM: The relationship between expectations and satisfaction in patients undergoing primary total knee arthroplasty. Arthroplasty. 2012, 27:490-2.

50. Stineman MG, Rist PM, Burke JP: Through the clinician's lens: Objective and subjective views of disability. Qual Health Res. 2009, 19:17-29.

51. Sarzi-Puttini P, Cimmino MA, Scarpa R, Caporali R, Parazzini F, Zaninelli A, et al. : Osteoarthritis: an overview of the disease and its treatment strategies . Semin Arthritis Rheum. 2005, 35:1-10.

52. Bullens PH, van Loon CJ, de Waal Malefijt MC, Laan RF, Veth RP: Patient satisfaction after total knee arthroplasty: a comparison between subjective and objective outcome assessments. J Arthroplasty. 2001, 16:740-7.

53. Minns Lowe CJM, Barker KL, Dewey ME, Sackley CM: Effectiveness of physiotherapy exercise following hip arthroplasty for osteoarthritis: a systematic review of clinical trials. BMC Musculoskeletal Disorders. 2009, 10:98. 10.1186/1471-2474-10-98

54. National Institutes of Health: National Institutes of Health consensus statement on total knee replacement : US Department of Health and Human Services. Bethesda, MD; 2004. 